This document is the Accepted Manuscript version of a Published Work that appeared in final form in Journal of Materials

Chemistry $C$ :

Benvenuti E, Gentili D, Chiarella F, Portone A, Barra M, Cecchini M, Cappuccino C, Zambianchi M, Lopez SG, Salzillo T, Venuti E, Cassinese A, Pisignano D, Persano L, Cavallini M, Maini L, Melucci M, Muccini M and Toffanin S. Tuning polymorphism in 2,3-thienoimide capped oligothiophene based field-effect transistors by implementing vacuum and solution deposition methods. J. Mater. Chem. C, 2018, 6, 5601.

(C) 2018 American Chemical Society after peer review and technical editing by the publisher.

To access the final edited and published work see http://doi.org/10.1039/c8tc00544c

\title{
Tuning polymorphism in 2,3-thienoimide capped oligothiophene based field-effect transistors by implementing vacuum and solution deposition methods
}

\author{
Emilia Benvenuti, $\quad$ *a Denis Gentili, $\quad$ *a Fabio Chiarella, ${ }^{\mathrm{b}}$ Alberto Portone, ${ }^{\mathrm{cd}}$ \\ Mario Barra, ${ }^{b}$ Marco Cecchini, $\quad{ }^{d}$ Chiara Cappuccino, $\quad$ Massimo Zambianchi, ${ }^{f}$ \\ Sergio G. Lopez, ${ }^{a}$ Tommaso Salzillo, ${ }^{g}$ Elisabetta Venuti, ${ }^{g}$ Antonio Cassinese, ${ }^{b}$ \\ Dario Pisignano, ${ }^{\text {dh }}$ Luana Persano, ${ }^{\text {d }}$ Massimiliano Cavallini, ${ }^{a}$ Lucia Maini, \\ Manuela Melucci, ${ }^{\dagger}$ Michele Muccini ${ }^{a}$ and Stefano Toffanin ${ }^{\star a}$
}

\begin{abstract}
We report on the investigation of the influence of the molecular packing and film morphology on the field-effect charge mobility in 2,3-thienoimide-based oligothiophenes semiconductors ( $\left.C_{n}-N T 4 N\right)$. Organic field-effect transistors are realized by implementing both vacuum and solution methods in order to control the solid-state phase of the active layer. Thermal sublimation in a high vacuum chamber and supersonic molecular beam deposition were used as vacuum-based fabrication approaches for preparing thin films, while lithographically controlled wetting was used, as a solution-deposition technique, for the fabrication of the microstructured films. Thermal sublimation leads to thin films with a phase packing showing ambipolar behaviour, while supersonic molecular beam deposition enables, by varying the deposition rate, the formation of two different crystal phases, showing ambipolar and unipolar field-effect behaviours. On the other hand, lithographically controlled wetting enables the formation of $\mathrm{C}_{n}-\mathrm{NT} 4 \mathrm{~N}$ microstructured active layers and their implementation in field-effect transistors.
\end{abstract}

\section{Introduction}

Polymorphism is emerging in organic optoelectronics as a powerful tool, alternate to molecular design, for controlling

\footnotetext{
${ }^{a}$ Istituto per lo Studio dei Materiali Nanostrutturati, Consiglio Nazionale delle Ricerche (CNR-ISMN), Via Gobetti 101, 40129 Bologna, Italy.

E-mail: denis.gentili@ismn.cnr.it, s.toffanin@bo.ismn.cnr.it

${ }^{b}$ CNR-SPIN e Dipartimento di Fisica, Università di Napoli Federico II,

Piazzale Tecchio 80, 80125 Napoli, Italy

'Dipartimento di Matematica e Fisica "Ennio De Giorgi", Università del Salento, via Arnesano 73100 , Lecce, Italy

${ }^{d}$ NEST, Istituto Nanoscienze-CNR, Piazza S. Silvestro 12, I-56127 Pisa, Italy

${ }^{e}$ Dipartimento di Chimica "G. Ciamician", Università di Bologna, Via F. Selmi 2, 40126, Bologna, Italy

${ }^{f}$ Istituto per la Sintesi Organica e la Fotoreattività, Consiglio Nazionale delle Ricerche (CNR-ISOF), Via Gobetti 101, 40129 Bologna, Italy

${ }^{g}$ Dipartimento di Chimica Industriale Toso Montanari, Università di Bologna, Viale del Risorgimento 4, 40136 Bologna, Italy.E-mail: ebenvenuti@bo.ismn.cnr.it

${ }^{h}$ Dipartimento di Fisica, Università di Pisa, Largo B. Pontecorvo 3, I-56127 Pisa, Italy
}

Electronic supplementary information (ESI) available: XRD patterns of $\mathrm{C}_{4}$-NT4N thin films deposited by thermal sublimation, transfer and output characteristics of OFETs based on $\mathrm{C}_{6}$-NT4N films deposited by LCW and thermal sublimation, XRD patterns of the $\mathrm{C}_{6}$-NT4N thin films deposited by drop casting, and confocal fluorescence image and localized emission spectra of $\mathrm{C}_{6}$-NT4N microstripes. See DOI: $10.1039 / \mathrm{c} 8 \mathrm{tc} 00544 \mathrm{c}$ the packing dependent functionalities of organic materials, such as optical, charge transport and optoelectronic properties. ${ }^{1}$ Polymorphic pentacenes, ${ }^{2,3}$ tetrathiafulvalenes $^{4,5}$ and rubrene ${ }^{6}$ materials have been widely investigated to study the influence of molecular packing on the charge transport capability in organic semiconductors. Recently, a clear relationship between the polymorph type and p-type mobility was established for fluorinated 5,11-bis(triethylsilylethynyl)anthradithiophene. ${ }^{7}$ Similarly, Kim et al. demonstrated polymorphism as a tool to control the optoelectronic and charge transport functionalities in two fluorene-based $\pi$-conjugated materials, ${ }^{8}$ while Wang et al. suggested the possibility of lasing in different colors by exploiting a single polymorphic $\left(4,4^{\prime}\right.$-(thiazolo[5,4- $\left.d\right]$-thiazole-2,5-diyl)bis( $N, N$-diphenylaniline $)$ ) compound. ${ }^{9}$

Tuning the optical, electrical and optoelectronic properties of organic semiconductors through the control of their polymorphic phases is particularly important for organic light emitting transistors (OLETs) ${ }^{10}$ whose electronic, optoelectronic and photonic multifunctionality strictly depends on the active material properties under operational conditions.

Thiophene molecular semiconductors are highly versatile organic materials, ${ }^{11,12}$ whose properties are representative of a broad range of organic semiconductor materials. 2,3-Thienoimide 

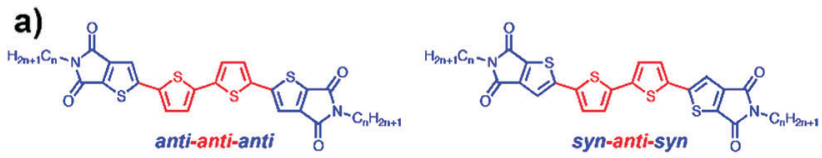

b)
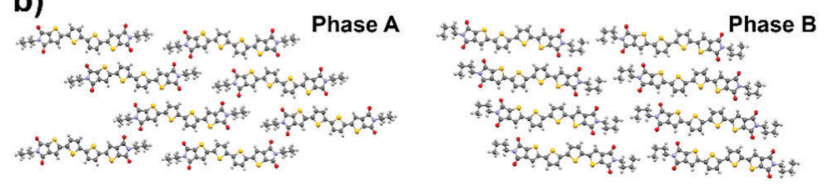

Fig. 1 (a) Molecular structure and conformational polymorphism types of the $\mathrm{C}_{n}$-NT4N semiconductors herein studied; (b) molecular packing.

end-capped oligothiophenes, also known as thienopyrrolyldionebased oligothiophenes $\left(\mathrm{C}_{n}\right.$-NT4N), show polymorphism ${ }^{13}$ and have the peculiarity of combining ambipolar semiconducting capability and electroluminescence, making them suitable materials for the fabrication of both ambipolar organic fieldeffect transistors (OFETs) ${ }^{14}$ and single-layer OLETs. ${ }^{15}$ A wide library of $\mathrm{C}_{n}$-NT4N compounds has been synthesized and characterized to study the effect of the $N$-alkyl end shape and size on the optical, self-assembly and charge transport properties. ${ }^{16}$ We have recently reported on the relationship between the molecular structures and polymorphism properties of $\mathrm{C}_{n}-\mathrm{NT} 4 \mathrm{~N}$ derivatives. ${ }^{17}$ Interestingly, $\mathrm{C}_{n}$-NT4N derivatives with an even number of carbon atoms in the alkyl end chains display at least two conformational polymorphs that adopt different molecular packings, namely phase $\mathrm{A}$ and phase $\mathrm{B}$, as a consequence of the different conformational arrangement of the 2,3-thienoimide end-moieties with respect to the adjacent thiophene core, i.e. anti or syn conformation (Fig. 1a). Consequently, while form A shows a columnar $\pi$-stacking packing, phase B shows a brick wall-like packing (Fig. 1b). ${ }^{17}$ The occurrence of different molecular packings may limit the reproducibility, stability, and reliability of devices based on these materials, therefore, the control of polymorph formation during film deposition is crucial for their applicability.

Herein, we report on the impact of the deposition technique on the charge transport properties of thin and microstructured films of 2,3-thienoimide-based molecular semiconductors and investigate their molecular packing, morphology and optical properties. We have chosen the butyl $\left(\mathrm{C}_{4}-\mathrm{NT} 4 \mathrm{~N}\right)$ and hexylended $\left(\mathrm{C}_{6}-\mathrm{NT} 4 \mathrm{~N}\right)$ oligomers because they are vacuum- and solution-processable semiconductors, respectively, and both exhibit polymorphism. Thermal sublimation in a high vacuum chamber and Supersonic Molecular Beam Deposition (SuMBD) were used as vacuum-based fabrication approaches for preparing thin films, while Lithographically Controlled Wetting (LCW) was used, as the solution-deposition technique, for the fabrication of microstructured films. We observed that thermal sublimation leads to thin films exhibiting ambipolar behaviour, while SuMBD enables the formation of both ambipolar and unipolar thin films. Ambipolar thin films are characterized by a polymorph B with brick-wall like packing, whereas unipolar thin films exhibit a new molecular packing that hampers the hole transport. We further demonstrated that spatial confinement of solution-deposition of 2,3-thienoimide capped oligothiophene achieved by LCW is an effective strategy for fabricating microstructured films with controlled features and suitable for their implementation in devices, overcoming the shortcomings of inhomogeneous films that are achieved by drop casting and spin coating. Solution-processed films of $\mathrm{C}_{6}$-NT4N were deposited from both anisole solution at $80{ }^{\circ} \mathrm{C}$ and 1,2-dichlorobenzene (1,2-DCB) solution at room temperature. The microstructured films exhibit ambipolar behaviour and are characterized by phase $\mathrm{B}$ regardless of the conditions used, while films deposited by drop casting at room temperature adopt the phase A structure, highlighting the key role of spatial confinement in the polymorphism control of wetdeposited $\mathrm{C}_{6}$-NT4N films.

\section{Results and discussion}

\section{Vacuum deposition}

Thin films of $\mathrm{C}_{4}$-NT4N were deposited by both vacuum thermal deposition and SuMBD and used as active layer of OFETs. OFETs were built in a bottom gate/bottom contact architecture using hexamethyldisilazane (HMDS)-treated $\mathrm{Si} / \mathrm{SiO}_{2}$ substrates to minimize charge trapping at the interface between the organic semiconductor and the dielectric ${ }^{18}$ and for guaranteeing a more hydrophobic interface suitable for $\mathrm{C}_{n}$-NT4N growth.

As demonstrated by the transfer characteristics in the saturation regime (Fig. 2a) and summarized in Table 1, thin films of $\mathrm{C}_{4}-\mathrm{NT} 4 \mathrm{~N}$ deposited at $0.1 \AA \mathrm{s}^{-1}$ by thermal sublimation exhibit ambipolar field-effect transport with saturated electron and hole mobilities up to $4.5 \times 10^{-2} \mathrm{~cm}^{2} \mathrm{~V}^{-1} \mathrm{~s}^{-1}$ and $6.7 \times 10^{-4} \mathrm{~cm}^{2} \mathrm{~V}^{-1} \mathrm{~s}^{-1}$, respectively. In agreement with a previous report on $\mathrm{C}_{4}-\mathrm{NT} 4 \mathrm{~N}$ deposited on
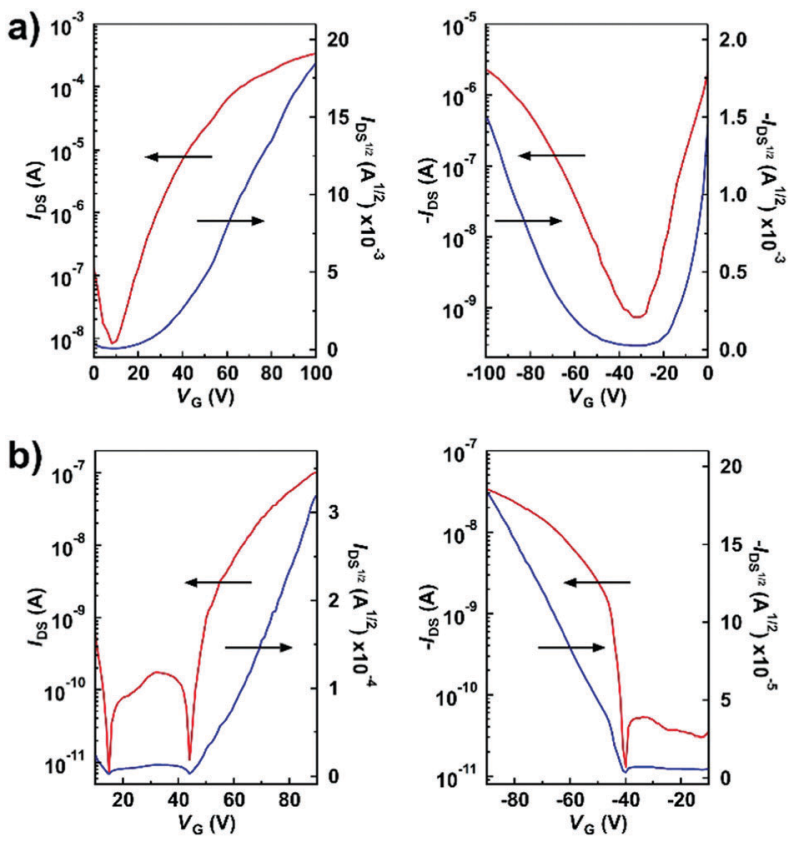

Fig. 2 Transfer characteristics measured at positive and negative sourcedrain bias of representative field-effect transistors based on $\mathrm{C}_{4}-\mathrm{NT} 4 \mathrm{~N}$ films deposited by thermal sublimation (a) and SuMBD (b) at $0.1 \AA \mathrm{s}^{-1}$ (drain voltage $V_{\mathrm{SD}}= \pm 100 \mathrm{~V}$ ). 
Table 1 Electrical data of bottom gate/bottom contact OFETs based on vapour-deposited films of $\mathrm{C}_{4}-\mathrm{NT} 4 \mathrm{~N}$

\begin{tabular}{|c|c|c|c|c|c|c|c|c|}
\hline & Rate $\left(\AA \mathrm{s}^{-1}\right)$ & Phase & $\mu_{\mathrm{e}}\left(\mathrm{cm}^{2} \mathrm{~V}^{-1} \mathrm{~s}^{-1}\right)$ & $V_{\text {th }}^{\mathrm{e}}(\mathrm{V})$ & $I_{\mathrm{on}}^{\mathrm{e}} / I_{\mathrm{off}}^{\mathrm{e}}$ & $\mu_{\mathrm{h}}\left(\mathrm{cm}^{2} \mathrm{~V}^{-1} \mathrm{~s}^{-1}\right)$ & $V_{\mathrm{th}}^{\mathrm{h}}(\mathrm{V})$ & $I_{\mathrm{on}}^{\mathrm{h}} / I_{\mathrm{off}}^{\mathrm{h}}$ \\
\hline Sublimation & 0.1 & B & $4.5 \times 10^{-2}$ & 58 & $10^{5}$ & $6.7 \times 10^{-4}$ & -72 & $10^{3}$ \\
\hline Sublimation & 0.017 & $\mathrm{~B}$ & $1.2 \times 10^{-2}$ & 61 & $10^{4}$ & $1.3 \times 10^{-4}$ & -67 & $10^{3}$ \\
\hline SuMBD & 0.1 & B & $1.2 \times 10^{-5}$ & 50 & $10^{4}$ & $2.2 \times 10^{-6}$ & -35 & $10^{3}$ \\
\hline SuMBD & 0.017 & $\mathrm{C}$ & $1.3 \times 10^{-4}$ & 53 & $10^{4}$ & - & - & - \\
\hline
\end{tabular}

PMMA films, ${ }^{16}$ XRD analysis reveals that thermal sublimation of $\mathrm{C}_{4}$-NT4N on HMDS-functionalized silicon dioxide yielded the phase B (Fig. S1, ESI †).

Moreover, considering that the bottom contact configuration is usually characterized by less effective charge injection than that of the top contact one, ${ }^{19}$ also the hole and electron carrier mobilities are in good agreement with what was previously reported. ${ }^{16}$ On the other hand, the threshold for electron transport is higher when HMDS-treated $\mathrm{SiO}_{2}$ was used instead of PMMA (i.e. a material with a low surface trapping density) as a dielectric layer, confirming that the electron traps cannot be completely passivated through the functionalization with HMDS. ${ }^{18}$ As reported in Table 1, the field-effect properties are not substantially affected by the decrease of the deposition rate, thin films of $\mathrm{C}_{4}$-NT4N grown by thermal deposition at $0.017 \AA_{\mathrm{s}}^{-1}$ exhibit ambipolar field-effect transport with mobilities and threshold voltages close to those obtained at higher rate. As revealed by XRD analysis (Fig. S1, ESI $\dagger$ ), these results are due to the fact that also at a low rate the films are composed of phase B. Beside vacuum thermal deposition, we have also investigated the deposition of $\mathrm{C}_{4}-\mathrm{NT} 4 \mathrm{~N}$ by SuMBD, which is an effective strategy to activate specific film growth ${ }^{20}$ since it allows a good control of the kinetic energy, $E_{\mathrm{k}}$, of the molecules impinging the growth surface. High performing n-type ${ }^{21}$ and $\mathrm{p}$-type $\mathrm{e}^{22}$ OFETs have been realized by this method as well as the controlled deposition of different polymorphic phases in titanyl phthalocyanine layers. ${ }^{23} \mathrm{C}_{4}$-NT4N was deposited with a kinetic energy $E_{\mathrm{k}}=12.4 \mathrm{eV}$, this being close to the saturation value that is theoretically predicted to be $13 \mathrm{eV}$. This feature induces a growth regime very far from equilibrium, where the roto-vibrational degrees of freedom of the molecules are frozen. $\mathrm{C}_{4}$-NT4N films deposited at $0.1 \AA \mathrm{s}^{-1}$ by SuMBD exhibit ambipolar behaviour, but yielded field-effect electron and hole mobilities in the saturation regime of $1.2 \times 10^{-5} \mathrm{~cm}^{2} \mathrm{~V}^{-1} \mathrm{~s}^{-1}$ and $2.2 \times 10^{-6} \mathrm{~cm}^{2} \mathrm{~V}^{-1} \mathrm{~s}^{-1}$, respectively, thus two orders of magnitude lower than what is observed for films deposited at the same deposition rate by thermal sublimation (Fig. $2 \mathrm{~b}$ and Table 1). Nevertheless, XRD measurements reported in Fig. 3b show that, in agreement with what was obtained with thermal deposition, the thin films of $\mathrm{C}_{4}$-NT4N deposited by SuMBD at $0.1 \AA \mathrm{s}^{-1}$ consist of phase $\mathrm{B}$. Therefore, the difference in electrical performance between films deposited by thermal sublimation and SuMBD can be explained in terms of the film morphology. Indeed, the film morphology assessed by AFM reveals that thin films deposited by thermal sublimation are characterized by growth of tridimensional crystals on continuous layers independent of deposition rate (Fig. 4a and b). In contrast, the morphology of thin films deposited by SuMBD is characterized by the coexistence of small grains with a lateral
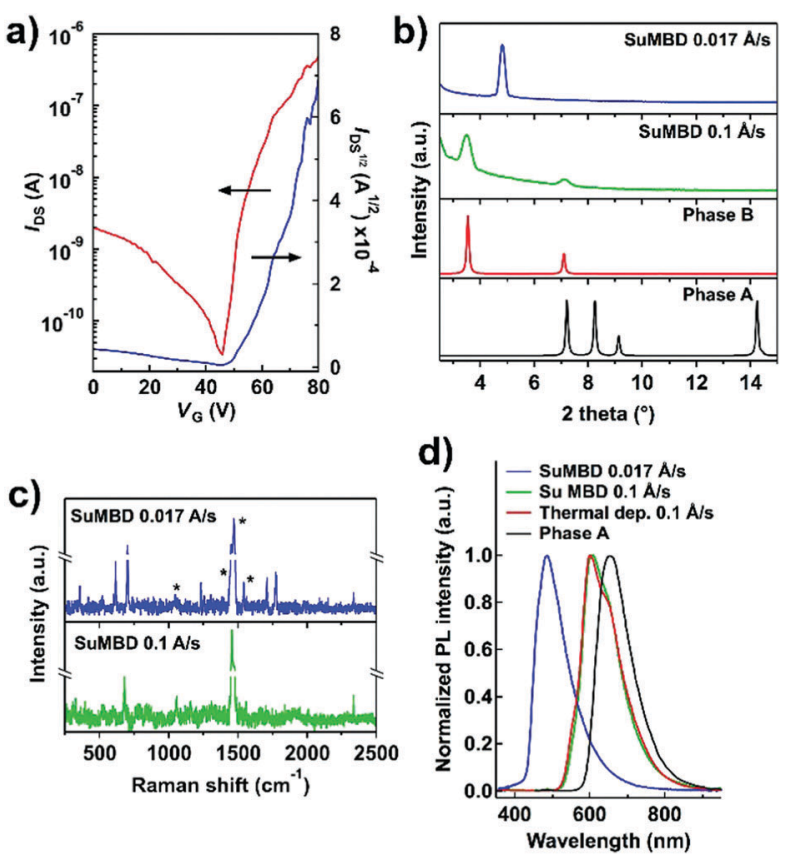

Fig. 3 (a) Transfer characteristics measured at positive source-drain bias of a representative field-effect transistor based on a $\mathrm{C}_{4}-\mathrm{NT4N}$ film deposited by SuMBD at $0.017 \AA \mathrm{s}^{-1}$ (drain voltage $V_{\mathrm{SD}}=100 \mathrm{~V}$ ). (b) XRD patterns of the $\mathrm{C}_{4}-\mathrm{NT} 4 \mathrm{~N}$ thin films deposited on $\mathrm{HMDS}$-treated $\mathrm{Si} / \mathrm{SiO}_{2}$ by SuMBD at 0.1 (green line) and $0.017 \AA \mathrm{s}^{-1}$ (blue line), and the calculated diffractograms of $A$ (black line) and $B$ (red line) phases. (c) Raman spectra of $\mathrm{C}_{4}-\mathrm{NT} 4 \mathrm{~N}$ thin films deposited on HMDS-treated $\mathrm{Si} / \mathrm{SiO}_{2}$ by SuMBD at 0.1 (green line) and $0.017 \AA \mathrm{s}^{-1}$ (blue line). (d) $\mathrm{PL}$ spectra of $\mathrm{C}_{4}-\mathrm{NT} 4 \mathrm{~N}$ thin films deposited on quartz by SuMBD at $0.017 \AA \mathrm{s}^{-1}$ (blue line) and at $0.1 \AA \mathrm{s}^{-1}$ (green line), and by thermal sublimation at $0.1 \AA \mathrm{s}^{-1}$ (red line), and $\mathrm{C}_{4}-\mathrm{NT} 4 \mathrm{~N}$ (phase A) powder (black line).

size lower than $100 \mathrm{~nm}$ and tridimensional structures (Fig. 4c). To investigate the effect of the deposition rate, we have also studied the field-effect properties of thin films deposited by SuMBD at a lower deposition rate, i.e. $0.017 \AA \mathrm{s}^{-1}$. In sharp contrast to the films deposited at $0.1 \AA \mathrm{s}^{-1}$, thin films of $\mathrm{C}_{4}$-NT4N grown at a low deposition rate show only an n-type field-effect response with a maximum mobility of about $10^{-4} \mathrm{~cm}^{2} \mathrm{~V}^{-1} \mathrm{~s}^{-1}$ (Fig. 3a and Table 1) and are characterized by rounded and well-defined terraced grains with steps close to $2 \mathrm{~nm}$, i.e. comparable with the length of $\mathrm{C}_{4}-\mathrm{NT} 4 \mathrm{~N}$ molecule (Fig. 4d). As shown in Fig. 3b, the XRD pattern of thin films deposited at $0.017 \AA \mathrm{s}^{-1}$ displays a unique peak at low angles (about $4.8^{\circ}$ ) that is not compatible with either phase A or B, revealing the presence of a polymorph with a different crystal structure, namely phase C. Therefore, as previously observed for other organic semiconductors, ${ }^{24,25}$ the absence of p-type 


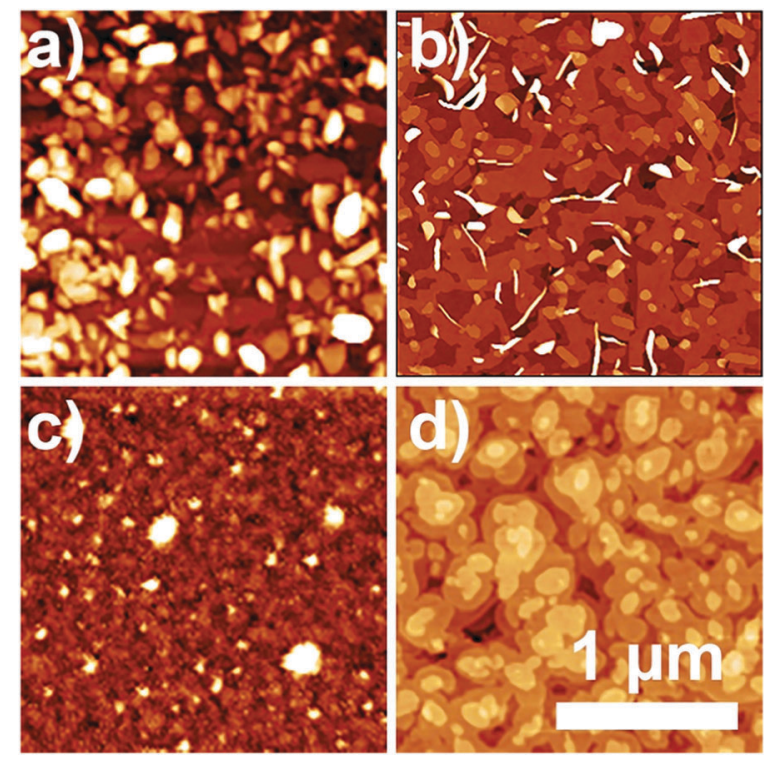

Fig. 4 AFM images of $\mathrm{C}_{4}-\mathrm{NT} 4 \mathrm{~N}$ films deposited on $\mathrm{HMDS}$-treated $\mathrm{Si} / \mathrm{SiO}_{2}$ by thermal sublimation at (a) $0.1 \AA \mathrm{s}^{-1}$ (z-scale: $\left.0-60 \mathrm{~nm}\right)$ and (b) $0.017 \AA \mathrm{s}^{-1}$ (z-scale: $0-30 \mathrm{~nm})$, and by SuMBD at (c) $0.1 \AA \mathrm{s}^{-1}(z$-scale: $0-15 \mathrm{~nm})$ and (d) $0.017 \AA \mathrm{s}^{-1}(z$-scale: $0-15 \mathrm{~nm})$.

behaviour can be ascribed to skeletal distortions of $\mathrm{C}_{4}-\mathrm{NT} 4 \mathrm{~N}$ molecules in the molecular packing of phase $\mathrm{C}$ that disrupt $\pi$-conjugation, as also supported by Raman and photophysical characterization (see below), and hinder the hole transport.

As shown in Fig. 3c, the Raman spectra of the thin films deposited by SuMBD with different deposition rates show different bands. The films grown at $0.1 \AA \mathrm{s}^{-1}$ are characterized by the specific Raman pattern, ranging between 1100 and $1400 \mathrm{~cm}^{-1}$, previously assigned to the phase B packing of the $\mathrm{C}_{n}$-NT4N molecules, whereas the films deposited at $0.017 \AA \mathrm{s}^{-1}$ do not show in the same spectral region the Raman features of either phase A or B. ${ }^{26}$ However, their spectrum displays the bands characteristic of the $\mathrm{C}_{n}$-NT4N molecules (see marks in the Fig. 3), revealing that the $\mathrm{C}_{n}$-NT4N chemical identity after the SuMBD process is fully preserved and thus confirming that the films consist of a new polymorph with a different molecular packing, i.e. the phase $\mathrm{C}$ packing. ${ }^{26}$ Interestingly, the Raman band of the phase $\mathrm{C}$ corresponding to the out of phase $\mathrm{C}=\mathrm{C}$ stretching mode $\left(\sim 1500 \mathrm{~cm}^{-1}\right),{ }^{27}$ which mainly involves displacements in the outermost rings of the oligothiophene skeleton, is shifted towards a higher frequency than that of the other phases. This is likely the indication of a lowering in the conjugation length that can be ascribed to a reduced planarity of the molecular structure. Unfortunately, attempts to obtain pure phase $\mathrm{C}$ in bulk were unsuccessful, suggesting that, as previously observed for other organic semiconductors, ${ }^{28}$ this polymorph might exist only in thin films.

The optical properties of the $\mathrm{C}_{4}$-NT4N films were investigated by photoluminescence spectroscopy. The PL spectra of the thin films of $\mathrm{C}_{4}$-NT4N deposited at $0.1 \AA^{-1} \mathrm{~s}^{-1}$ by both vacuum thermal deposition and SuMBD reveal the characteristic emission features expected for phase $\mathrm{B},{ }^{17}$ consisting of an emission band centered at about $600 \mathrm{~nm}$ (Fig. 3c, red and green lines). In sharp contrast, the films of $\mathrm{C}_{4}-\mathrm{NT} 4 \mathrm{~N}$ deposited at $0.017 \AA \mathrm{s}^{-1}$ by SuMBD show an emission band centered at $488 \mathrm{~nm}$ and are thus blue-shifted compared to the characteristic PL emission of A and B polymorphs of $\mathrm{C}_{4}$-NT4N (Fig. 3c, blue line). ${ }^{17}$ Therefore, in good agreement with the XRD and Raman measurements, the photophysical properties indicate that the thin films of $\mathrm{C}_{4}$-NT4N obtained at $0.017 \AA \mathrm{s}^{-1}$ by SuMBD are composed of a new phase in which, probably due to the energetics of the supersonic beam, the molecular moieties are arranged in a sterically hindered configuration so that the $\pi-\pi$ delocalization in the crystalline domains is reduced. However, as demonstrated by the electrical characterization, the molecular moieties are arranged according to a solid-state configuration that preserves the efficient overlapping of $\pi$ orbitals $^{29}$ to allow lateral electron transport in FET devices.

\section{Solution deposition}

Previous studies carried out by our group demonstrated that both the drop casting and spin coating of solution of $\mathrm{C}_{n}-\mathrm{NT} 4 \mathrm{~N}$ molecules lead to the formation of needle shaped microcrystals unsuitable for the fabrication of OFETs. ${ }^{17}$ In light of that, we have exploited an unconventional wet lithographic technique, i.e. Lithographically Controlled Wetting (LCW), to pattern and study the electrical properties of $\mathrm{C}_{6}-\mathrm{NT} 4 \mathrm{~N}$, as it is the most soluble of the $\mathrm{C}_{n}$-NT4N series. ${ }^{16}$

LCW is a stamp-assisted technique that exploits the selforganizing properties of the materials in a spatially confined system for creating micro and nanostructured thin films replicating the stamp features. LCW has been successfully employed for the integration of soluble organic and metalorganic compounds in OFETs. ${ }^{30,31}$ Since attempts to implement microstructured films in bottom gate/bottom contact transistors have been unsuccessful, OFETs based on microstripes of $\mathrm{C}_{6}$-NT4N were fabricated by LCW in a bottom gate/top contact configuration, i.e. the best performing configuration for $\mathrm{a} \mathrm{C}_{n}$-NT4N based device, ${ }^{16}$ using a perfluorinated polymer (Cytop) as dielectric layer to guarantee the solvent orthogonality (Fig. 5a). All the steps of fabrication were performed under a controlled atmosphere in order to prevent the degradation phenomena activated by oxygen and water. As shown in Fig. 5b, $\mathrm{C}_{6}$-NT4N microstripes ( $\sim 80 \mathrm{~nm}$ high) with a controlled size, shape, and orientation were successfully fabricated by LCW using anisole solution at $80{ }^{\circ} \mathrm{C}$ and 1,2-dichlorobenzene (1,2-DCB) as solvent at room temperature. The temperature was optimized in order to enhance the solubility and allow the formation of long-range molecular ordered stripes.

Fig. 5c, d and Fig. S2, ESI $\dagger$ show the transfer and output characteristics of the $\mathrm{C}_{6}-\mathrm{NT} 4 \mathrm{~N}$ based devices fabricated by LCW. The output characteristics curves exhibit the superimposition of standard saturation behaviour for one charge carrier and a superlinear current increase due to injection of the other charge carrier, indicative of the typical ambipolar transport behaviour expected for $\mathrm{C}_{6}-\mathrm{NT} 4 \mathrm{~N}$.

In Table 2 the electrical performance of the devices fabricated both by LCW and, for comparison, by thermal sublimation of $\mathrm{C}_{6}$-NT4N (Fig. S3, ESI $\dagger$ ) are summarized. All the devices exhibit 
a)
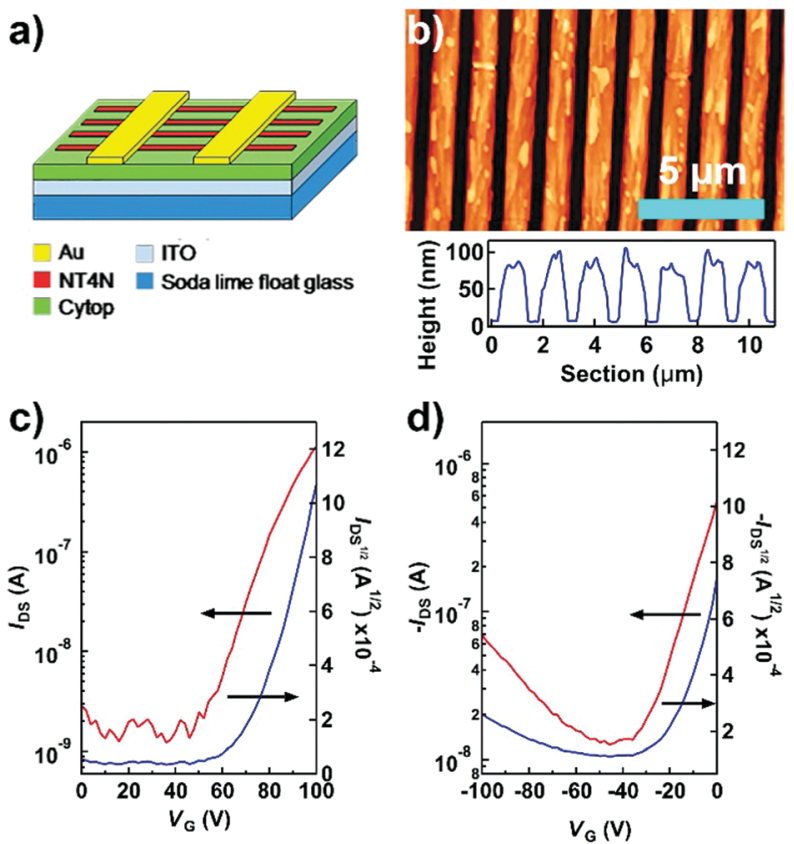

Fig. 5 (a) Schematic representation of a bottom gate/top contact OFET based on $\mathrm{C}_{6}$-NT4N microstripes. (b) AFM image of $\mathrm{C}_{6}$-NT4N depositated on Cytop by LCW from anisole solution ( $z$-scale: $0-150 \mathrm{~nm}$ ) and the corresponding profile. Transfer characteristics measured at a positive or negative source-drain bias of a representative field-effect transistor based on $\mathrm{C}_{6}-\mathrm{NT} 4 \mathrm{~N}$ deposited by LCW from (c) anisole and (d) 1,2-DCB solution (drain voltage $V_{S D}= \pm 100 \mathrm{~V}$ ).

unbalanced field-effect charge transport, but the solventprocessed microstructured $\mathrm{C}_{6}$-NT4N films yielded lower fieldeffect performance than the vapor-deposited films. Microstripes of $\mathrm{C}_{6}-\mathrm{NT} 4 \mathrm{~N}$ deposited from anisole solution exhibit electron and hole mobilities in the saturation regime of $2.4 \times 10^{-3} \mathrm{~cm}^{2} \mathrm{~V}^{-1} \mathrm{~s}^{-1}$ and $1.0 \times 10^{-5} \mathrm{~cm}^{2} \mathrm{~V}^{-1} \mathrm{~s}^{-1}$, respectively, but using 1,2-DCB solution the electron mobility decreases by one order of magnitude. Noteworthily, thin films of $\mathrm{C}_{6}$-NT4N deposited on Cytop by thermal sublimation showed an electrical performance (Table 2) similar to those that have been reported using PMMA as a dielectric layer. ${ }^{16}$ XRD analysis shows that microstructured films of $\mathrm{C}_{6}$-NT4N deposited from anisole solution are characterized by only polymorph $\mathrm{B}$, while the XRD pattern of films deposited from 1,2-DCB solution displays a profile with a doublet for the peak at $2 \theta \sim 6.1^{\circ}$ revealing the coexistence of both A and B phases (Fig. 6a). In addition, it shows two not identified and correlated peaks at $2 \theta=2.2^{\circ}$ and $4.4^{\circ}$ (respectively $d=44.6$ and $22.3 \AA$ ) that possibly refer to the same family of crystalline planes. Noteworthily, the similarity between the peak at $2 \theta=4.4^{\circ}$ with the peak at $2 \theta=4.8^{\circ}$ of
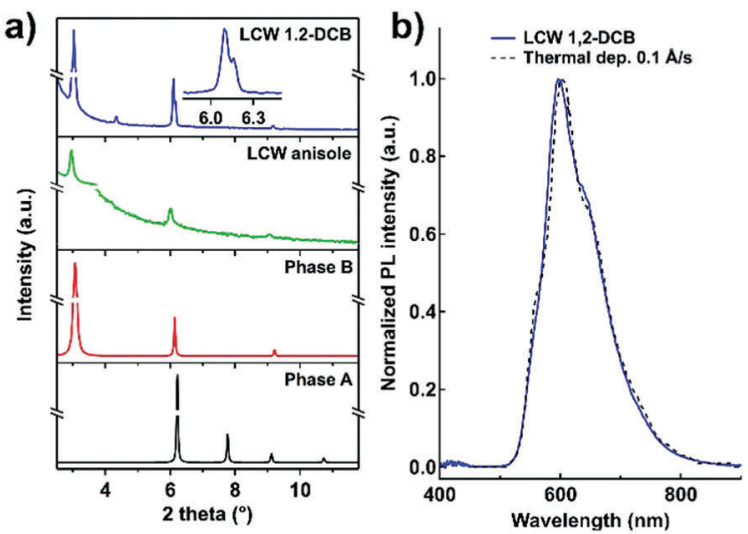

Fig. 6 (a) XRD patterns of the $\mathrm{C}_{6}$-NT4N microstripes deposited on Cytop by LCW from 1,2-DCB (blue line) and anisole (green line) solution, and calculated diffractograms of $\mathrm{A}$ (black line) and $\mathrm{B}$ (red line) phases. (b) PL spectra of $\mathrm{C}_{6}-\mathrm{NT} 4 \mathrm{~N}$ microstripes deposited on Cytop by LCW from 1,2DCB (blue line) and $\mathrm{C}_{6}-\mathrm{NT} 4 \mathrm{~N}$ thin film deposited on Cytop by thermal sublimation at $0.1 \AA^{-1}$ (black dashed line).

the phase $\mathrm{C}_{\text {of }} \mathrm{C}_{4}$-NT4N (Fig. 3b) suggests the presence of a polymorph of $\mathrm{C}_{6}-\mathrm{NT} 4 \mathrm{~N}$ with a similar molecular packing. Therefore, this mixed composition of phases may explain the worse performance of microstructured films of $\mathrm{C}_{6}-\mathrm{NT} 4 \mathrm{~N}$ deposited from 1,2-DCB solution.

To investigate the role of spatial confinement on the selection of phase packing, XRD analysis of $\mathrm{C}_{6}$-NT4N solution-cast films was performed. As expected, after solvent evaporation $\mathrm{C}_{6}$-NT4N forms needle-shaped microcrystals, but while the crystals deposited from the anisole solution at $80{ }^{\circ} \mathrm{C}$ exhibit a XRD profile compatible with phase $\mathrm{B}$, the crystals achieved from 1,2-DCB solution at room temperature exhibit phase A (Fig. S4, ESI $\dagger$ ). Similarly, it has been previously reported that the crystals of $\mathrm{C}_{6}-\mathrm{NT} 4 \mathrm{~N}$ prepared from toluene solution at room temperature are characterized by phase A, but after thermal treatment, the conversion to phase $\mathrm{B}$ occurs. ${ }^{17}$ Therefore, considering that the two phases are enantiotropically related and, at room temperature, the stable phase is $\mathrm{A}^{17}$ our results suggest that the formation of phase $\mathrm{B}$ in microstructured films of $\mathrm{C}_{6}$-NT4N deposited using anisole at $80{ }^{\circ} \mathrm{C}$ can be mainly ascribed to the thermal treatment; while differently, in the case of microstructured films deposited at room temperature from 1,2-DCB solution, the preferential growth of phase B is induced by the spatial confinement. ${ }^{32}$

Noteworthily, photoluminescence spectroscopy showed that $\mathrm{C}_{6}$-NT4N microstripes deposited on Cytop by LCW from 1,2-DCB solution exhibit the emission profile of the phase B (Fig. 6b) as also confirmed by the localized emission spectra collected in different areas of the microstructured film (Fig. S5, ESI $\dagger$ ).

Table 2 Electrical data of bottom gate/top contact OFETs based on solution-deposited films of $\mathrm{C}_{6}$-NT4N

\begin{tabular}{llllllll}
\hline & Solvent & Phase & $\mu_{\mathrm{e}}\left(\mathrm{cm}^{2} \mathrm{~V}^{-1} \mathrm{~s}^{-1}\right)$ & $I_{\text {on }}^{\mathrm{e}} / I_{\text {off }}^{\mathrm{e}}$ & $V_{\text {th }}^{\mathrm{e}}(\mathrm{V})$ & $\mu_{\mathrm{h}}\left(\mathrm{cm}^{2} \mathrm{~V}^{-1} \mathrm{~s}^{-1}\right)$ & $V_{\mathrm{th}}^{\mathrm{h}}(\mathrm{V})$ \\
\hline LCW & Anisole & B & $2.4 \times 10^{-3}$ & $10^{3}$ & 62 & $1.0 \times 10^{-5}$ & -56 \\
LCW & $1,2-\mathrm{DCB}$ & B (A) & $4.4 \times 10^{-4}$ & $10^{2}$ & 60 & $2.7 \times 10^{-5}$ & -64 \\
Sublimation & - & B & $2.0 \times 10^{-1}$ & $10^{4}$ & 57 & $2.2 \times 10^{-3}$ & $10^{1}$ \\
\hline
\end{tabular}


We point out that the intensity of the PL spectra is correlated not only to the amount of emissive material present in the film, but also to the PL quantum yield of each phase, which is likely the basis of the difficulty to optically unveil phase $A$ in the microstructured material.

\section{Experimental}

Materials

$\mathrm{C}_{n}$-NT4N compounds were synthesized according to the literature. ${ }^{17}$ Hexamethyldisilazane (HMDS) and spectroscopic grade quality solvents were purchased from Sigma-Aldrich. Sylgard 184 (polydimethylsiloxane, PDMS) silicone elastomer base and the curing agent were purchased from Dow Corning. CYTOP CTL-809M was purchased from AGC chemicals.

\section{Device fabrication}

Bottom gate/bottom contact transistors were fabricated on heavily n-type doped silicon (100) wafers with a $200 \mathrm{~nm}$ thermally grown silicon dioxide dielectric layer $\left(C_{\mathrm{i}}=17.25 \mathrm{nF} \mathrm{cm}{ }^{-2}\right)$. Gold source-drain electrodes (100 nm thick) with a width/ length ratio of 550 were deposited by vacuum evaporation and patterned by photolithography. Before the deposition of the semiconductor, the substrates were cleaned by sonication in acetone for $10 \mathrm{~min}$, then in 2-propanol for $10 \mathrm{~min}$, and functionalized with HMDS. ${ }^{33}$

Bottom gate/top contact transistors were fabricated on glass/ ITO/Cytop substrates where ITO and Cytop (450 nm) were used as the gate electrode and gate dielectric, respectively. Before the deposition of Cytop, the substrates were cleaned by ultrasonic baths in acetone, then 2-propanol and dried under a nitrogen flow. Gold source-drain electrodes (70 nm thick) were deposited by thermal evaporation onto the semiconductor films through a shadow mask at room temperature and $10^{-6}$ mbar. Devices were fabricated with $12 \mathrm{~mm}$ channel width and $70 \mu \mathrm{m}$ channel length.

Vacuum deposition of $\sim 30 \mathrm{~nm}$ thick layers of $\mathrm{C}_{4}$-NT4N was performed by thermal deposition and SuMBD keeping the substrate at room temperature. The organic precursor vapor for SuMBD was produced in a quartz tube by thermal evaporation with a stagnation pressure of He gas of about 1300 mbar. Molecular vapor was seeded in a supersonic jet of the He carrier gas, resulting in a kinetic energy $\left(E_{\mathrm{k}}\right)$ value of the emerging molecular beam of approximately $12.4 \mathrm{eV}$ per molecule.

Solution deposition of $\mathrm{C}_{6}$-NT4N was performed by LCW. ${ }^{32}$ Elastomeric polydimethylsiloxane (PDMS) molds were prepared by replica molding of Compact Disk supports or silicon masters. The stamp motifs consist of parallel lines $1 \mu \mathrm{m}$ wide, $230 \pm 15 \mathrm{~nm}$ deep and $1.7 \mu \mathrm{m}$ periodicity. After curing for $6 \mathrm{~h}$ at $60{ }^{\circ} \mathrm{C}$, PDMS stamps were peeled off, cleaned by sonication in ethanol for $10 \mathrm{~min}$, and dried under nitrogen flow. $5 \mu \mathrm{L}$ of saturated solution of $\mathrm{C}_{6}$-NT4N in anisole at $80{ }^{\circ} \mathrm{C}$ or 1,2-dichlorobenzene at room temperature were drop cast on the substrate, then a PDMS stamp was placed on the top, paying attention to the stripe orientation, and the solvent was allowed to evaporate under nitrogen for $24 \mathrm{~h}$. For anisole solution, the substrates were heated on a hot plate at $80{ }^{\circ} \mathrm{C}$ during film deposition. Afterwards, the stamp was removed and, before characterization, the samples were aged under a nitrogen atmosphere for 2 hours.

\section{Electrical characterization}

The electrical measurements were carried out in a MBraun nitrogen glovebox using a standard SUSS probe station coupled to a B1500A Agilent semiconductor device analyser. The fieldeffect mobility in the saturation regime $\left(\mu_{\text {sat }}\right)$ was calculated using the equation $I_{\mathrm{DS}}=(W / 2 L) C_{\mathrm{i}} \mu_{\text {sat }}\left(V_{\mathrm{G}}-V_{\mathrm{T}}\right)^{2}$, where $W$ and $L$ are the channel widths and lengths, respectively, $C_{\mathrm{i}}$ is the capacitance per unit area of the insulating layer, and $V_{\mathrm{T}}$ is the threshold voltage extracted from the square root of the drain current $\left(I_{\mathrm{DS}}{ }^{1 / 2}\right)$ versus the gate voltage $\left(V_{\mathrm{G}}\right)$ characteristics for a fixed drain voltage $\left(V_{\mathrm{DS}}\right)$. For solution-processed devices, the effective channel widths were estimated on the basis of the statistical analysis of optical microscopy images.

\section{Optical characterization}

Steady-state photo-luminescence (PL) was excited using a CW $\mathrm{He}-\mathrm{Cd}$ laser at a wavelength of $325 \mathrm{~nm}$ and collected under transmission conditions (no color filter was necessary for truncating laser excitation). PL emission was collected using a calibrated optical multichannel analyzer (PMA-11, Hamamatsu). CLSM images of the microstructured active layer and localized photoluminescence measurements were obtained with a Nikon Eclipse 2000-E laser scanning confocal microscope using an excitation wavelength of $405 \mathrm{~nm}$.

\section{XRD characterization}

X-ray data were collected using a PANalyticalX'Pert PRO diffractometer in Bragg-Brentano configuration equipped with a X'Celerator detector with $\mathrm{Cu} \mathrm{K} \alpha(\lambda=1.5418 \AA)$ as the incident radiation. Soller $0.04 \mathrm{rad}$, Anti-scatter slit 1/8, divergence slit 1/16, step size $0.017^{\circ}$.

\section{Raman characterization}

Raman spectra were recorded with the Renishaw System InVia spectrometer equipped with a Peltier cooled CCD. The spectrometer was coupled to a Leica DLML microscope equipped with $50 \times, 20 \times$ and $5 \times$ objectives which allowed for a spatial resolution of about $1 \mu \mathrm{m}$ with the $50 \times$ objective and a nominal field depth ranging from about 25 to $450 \mu \mathrm{m}$. The excitation was from a diode laser tuned at $785 \mathrm{~nm}$ with a nominal power of $500 \mathrm{~mW}$. The power was reduced by neutral density filters to avoid sample damage.

\section{Morphology measurements}

AFM images were collected at room temperature in air on a Multimode 8 microscope operated in PeakForce mode and equipped with a type $\mathrm{J}$ scanner (Bruker Nano Inc. $\mathrm{GmbH}$ ) and SNL-A probes with a nominal spring constant of $0.35 \mathrm{~N} \mathrm{~m}^{-1}$ (Bruker AFM Probes, Camarillo, CA), or on an XE-100 microscope operated in non-contact mode (Park systems) and equipped with a silicon nitride cantilever (Nanosensors). Background interpolation was performed with Gwyddion 2.48 (http://gwyddion.net/). 


\section{Conclusions}

In this study, we have investigated the impact of the processing method in controlling the polymorphism of two 2,3-thienoimidebased oligothiophenes semiconductors $\left(\mathrm{C}_{4^{-}}\right.$and $\left.\mathrm{C}_{6}-\mathrm{NT} 4 \mathrm{~N}\right)$ that are typically implemented in the fabrication of multifunctional field-effect transistors. Giving the possibility of $\mathrm{C}_{n}$-NT4N derivatives for being processed by both vacuum and solution methods, the polymorphism was probed and revealed by choosing different deposition techniques, i.e. thermal sublimation, SuMBD and LCW. While thermal sublimation leads to phase B showing an ambipolar behaviour, SuMBD enables, by varying the deposition rate, the formation of both phase $\mathrm{B}$ and a new form, named $\mathrm{C}$, showing unipolar field-effect behaviour. Moreover, comparing thin films with the same molecular packing, but deposited by different techniques, we highlighted the fundamental role of film morphology on their electrical performance.

On the other hand, the use of a stamp-assisted technique such as LCW was fundamental in the fabrication of the device since it enables the realization of a microstructured active layer, thus overcoming the inhomogeneity achieved by drop casting and spin coating. In particular, microstructured thin films were deposited from anisole at $80{ }^{\circ} \mathrm{C}$ and from 1,2 DCB at room temperature. While drop casting at room temperature leads to phase A, the LCW preferentially leads to phase B, showing the importance of the spatial confinement in controlling the polymorphism. For the first time, we succeeded in demonstrating field-effect charge transport for the $\mathrm{C}_{n}$-NT4N derivative deposited from solution.

In conclusion, our study confirms that the process of deposition, with control of the polymorph type and the morphological features, may represent a straightforward and effective way to tune the electrical properties of 2,3-thienoimide-ended materials.

\section{Conflicts of interest}

There are no conflicts to declare.

\section{Acknowledgements}

This work received funding from the European Union's Horizon 2020 research and innovation program under grant agreement no. 644742 (LEO Project) and from the national project "Premiale" EOS funded by Italian Ministero dell'Istruzione dell'Università e della Ricerca (MIUR). D. G. was supported by the Italian flagship NANOMAX, N-CHEM. The authors thank F. Gallino (SEAS Getters) for the helpful discussion. Finally, we are grateful to F. Prescimone and V. Ragona (CNR-ISMN) for the valuable technical contributions.

\section{Notes and references}

1 H. Chung and Y. Diao, J. Mater. Chem. C, 2016, 4, 3915-3933. 2 A. Troisi and G. Orlandi, J. Phys. Chem. B, 2005, 109, 1849-1856.

3 D. J. Gundlach, T. N. Jackson, D. G. Schlom and S. F. Nelson, Appl. Phys. Lett., 1999, 74, 3302-3304.
4 H. Jiang, X. Yang, Z. Cui, Y. Liu, H. Li, W. Hu, Y. Liu and D. Zhu, Appl. Phys. Lett., 2007, 91, 123505.

5 R. Pfattner, M. Mas-Torrent, I. Bilotti, A. Brillante, S. Milita, F. Liscio, F. Biscarini, T. Marszalek, J. Ulanski, A. Nosal, M. Gazicki-Lipman, M. Leufgen, G. Schmidt, W. M. Laurens, V. Laukhin, J. Veciana and C. Rovira, Adv. Mater., 2010, 22, 4198-4203.

6 O. D. Jurchescu, A. Meetsma and T. T. M. Palstra, Electrochem. Solid-State Lett., 2006, 9, 330-334.

7 O. D. Jurchescu, D. a. Mourey, S. Subramanian, S. R. Parkin, B. M. Vogel, J. E. Anthony, T. N. Jackson and D. J. Gundlach, Phys. Rev. B: Condens. Matter Mater. Phys., 2009, 80, 85201.

8 J. Y. Kim, T. Yasuda, Y. S. Yang, N. Matsumoto and C. Adachi, Chem. Commun., 2014, 50, 1523-1526.

9 K. Wang, H. Zhang, S. Chen, G. Yang, J. Zhang, W. Tian, Z. Su and Y. Wang, Adv. Mater., 2014, 26, 6168-6173.

10 M. Muccini, W. Koopman and S. Toffanin, Laser Photonics Rev., 2012, 6, 258-275.

11 I. F. Perepichka and D. F. Perepichka, Handbook of Thiophene Based Materials, 2009.

12 L. Zhang, N. S. Colella, B. P. Cherniawski, S. C. B. Mannsfeld and A. L. Briseno, ACS Appl. Mater. Interfaces, 2014, 6, 5327-5343.

13 M. Zambianchi, L. Favaretto, M. Durso, C. Bettini, A. Zanelli, I. Manet, M. Gazzano, L. Maini, D. Gentili, S. Toffanin, F. Gallino, M. Muccini, M. Cavallini and M. Melucci, J. Mater. Chem. C, 2015, 3, 121-131.

14 M. Durso, C. Bettini, A. Zanelli, M. Gazzano, M. G. Lobello, F. De Angelis, V. Biondo, D. Gentili, R. Capelli, M. Cavallini, S. Toffanin, M. Muccini and M. Melucci, Org. Electron., 2013, 14, 3089-3097.

15 M. Natali, S. D. Quiroga, L. Passoni, L. Criante, E. Benvenuti, G. Bolognini, L. Favaretto, M. Melucci, M. Muccini, F. Scotognella, F. Di Fonzo and S. Toffanin, Adv. Funct. Mater., 2017, 27, 1-8.

16 M. Melucci, M. Durso, C. Bettini, M. Gazzano, L. Maini, S. Toffanin, S. Cavallini, M. Cavallini, D. Gentili, V. Biondo, G. Generali, F. Gallino, R. Capelli and M. Muccini, J. Mater. Chem. C, 2014, 2, 3448-3456.

17 L. Maini, F. Gallino, M. Zambianchi, M. Durso, M. Gazzano, K. Rubini, D. Gentili, I. Manet, M. Muccini, S. Toffanin, M. Cavallini and M. Melucci, Chem. Commun., 2015, 51, 2033-2035.

18 L.-L. Chua, J. Zaumseil, J.-F. Chang, E. C.-W. Ou, P. K.H. Ho, H. Sirringhaus and R. H. Friend, Nature, 2005, 434, 194-199.

19 K. Noda, Y. Wada and T. Toyabe, Org. Electron., 2014, 15, 1571-1578.

20 K. Walzer, T. Fritz and K. Leo, Surf. Sci., 2006, 600, 2064-2069.

21 F. Chiarella, T. Toccoli, M. Barra, L. Aversa, F. Ciccullo, R. Tatti, R. Verucchi, S. Iannotta and A. Cassinese, Appl. Phys. Lett., 2014, 104, 143302.

22 Y. Wu, T. Toccoli, N. Koch, E. Iacob, A. Pallaoro, P. Rudolf and S. Iannotta, Phys. Rev. Lett., 2007, 98, 1-4. 
23 N. Coppedè, E. Bonnini, F. Mezzadri, G. Tarabella, P. Ranzieri, L. Barba, G. Arrighetti, L. Lutterotti and S. Iannotta, Org. Electron. Physics, Mater. Appl., 2016, 32, 15-20.

24 A. Facchetti, T. J. Marks and Y. Zheng, J. Am. Chem. Soc., 2010, 132, 8440-8452.

25 S. Thankaraj Salammal, Z. Zhang, J. Chen, B. Chattopadhyay, J. Wu, L. Fu, C. Fan and H. Chen, ACS Appl. Mater. Interfaces, 2016, 8, 20916-20927.

26 C. Cappuccino, P. P. Mazzeo, T. Salzillo, E. Venuti, A. Giunchi, R. G. Della Valle, A. Brillante, C. Bettini, M. Melucci and L. Maini, Phys. Chem. Chem. Phys., 2018, 20, 3630-3636.

27 J. Casado, V. Hernandez, R. Ponce Ortiz, M. C. Ruiz Delgado, J. T. Lopez Navarrete, G. Fuhrmann and P. Bauerle, J. Raman Spectrosc., 2004, 35, 592-599.

28 A. M. Hiszpanski, R. M. Baur, B. Kim, N. J. Tremblay, C. Nuckolls, A. R. Woll and Y. L. Loo, J. Am. Chem. Soc., 2014, 136, 15749-15756.
29 M. Muccini and S. Toffanin, Organic Light-Emitting Transistors: Towards the Next Generation Display Technology, WileyScience, Wise Co-Publication, Wiley, 2016.

30 D. Gentili, F. Di Maria, F. Liscio, L. Ferlauto, F. Leonardi, L. Maini, M. Gazzano, S. Milita, G. Barbarella and M. Cavallini, J. Mater. Chem., 2012, 22, 20852-20856.

31 A. de la Peña Ruigõmez, D. Rodríguez-San-Miguel, K. C. Stylianou, M. Cavallini, D. Gentili, F. Liscio, S. Milita, O. M. Roscioni, M. L. Ruiz-González, C. Carbonell, D. Maspoch, R. Mas-Ballesté, J. L. Segura and F. Zamora, Chem. - Eur. J., 2015, 21, 10666-10670.

32 D. Gentili, F. Valle, C. Albonetti, F. Liscio and M. Cavallini, Acc. Chem. Res., 2014, 47, 2692-2699.

33 M. Barra, D. Viggiano, P. Ambrosino, F. Bloisi, F. V. Di Girolamo, M. V. Soldovieri, M. Taglialatela and A. Cassinese, Biochim. Biophys. Acta, Gen. Subj., 2013, 1830, 4365-4373. 